\title{
Comprehensive Evaluation for Cold Tolerance in Wucai (Brassica campestris L.) by the Performance Index on an Absorption Basis (PIabs)
}

\author{
Yun Dai ${ }^{1,2}$, Lingyun Yuan ${ }^{1,3,4}$, Shujiang Zhang ${ }^{2}$, Jie Wang ${ }^{1}$, Shilei Xie ${ }^{1}$, Mengru Zhao ${ }^{1}$, \\ Guohu Chen $1,3,4$, Rifei Sun $2, * \mathbb{B}$ and Chenggang Wang $1,3,4, * \mathbb{D}$ \\ 1 College of Horticulture, Vegetable Genetics and Breeding Laboratory, Anhui Agricultural University, \\ Changjiang West Road, NO.130, Hefei 230036, China; DaiYun1210@126.com (Y.D.); ylyun99@163.com (L.Y.); \\ 17720092@ahau.edu.cn (J.W.); fyxs1@ahau.edu.cn (S.X.); 17720095@ahau.edu.cn (M.Z.); \\ cgh@ahau.edu.cn (G.C.) \\ 2 Institute of Vegetables and Flowers, Chinese Academy of Agricultural Sciences, Beijing 100081, China; \\ zhangshujiang@caas.cn \\ 3 Provincial Engineering Laboratory for Horticultural Crop Breeding of Anhui, Hefei 230036, China \\ 4 Wanjiang Vegetable Industrial Technology Institute, Maanshan 238200, China \\ * Correspondence: sunrifei@caas.cn (R.S.); cgwang@ahau.edu.cn (C.W.)
}

Received: 27 December 2018; Accepted: 28 January 2019; Published: 30 January 2019

\begin{abstract}
Wucai is a biannual leafy vegetable that is more sensitive to cold than most Brassicaceae vegetables. Here, phenotypic differences in wucai were investigated to identify those genotypes with high cold tolerance at low temperature, which could allow their cultivation in cold climates. In all, on the basis of PIabs, 20 wucai genotypes (10 lower PIabs and 10 higher PIabs) were selected from a collection of 124 genotypes. Both W16-13 and SW-3 (higher PIabs) and the LS-6 and W15-16 (lower PIabs) were screened from the 20 wucai genotypes according to several key plant physiological traits: net photosynthetic rate, electrolyte leakage, chilling injury index, specific leaf area, malondialdehyde contents, and PIabs. To further verify the reliability of PIabs, four genotypes were grown under low temperature gradient conditions and their morphological indexes, chlorophyll content, total antioxidant capacity, fluorescence transients (OJIP transients), leaf cell ultrastructure, and gene expression were measured. These indicators strongly demonstrated that the W16-13 and SW-3, which had higher PIabs, possessed higher resistance to cold stress, while both LS-6 and W15-16 were sensitive to cold. As this study shows, the easily measured performance index, PIabs, could be applied to wucai genotypes to screen for one or more varieties characterized by higher cold tolerance.
\end{abstract}

Keywords: cold tolerance; cold tolerance indicator; PIabs; wucai

\section{Introduction}

Wucai (Brassica campestris L. ssp. Chinensis var. Rosularis Tsen et Lee.), a type of Chinese cabbage with high nutritional value, is an important vegetable crop farmed in the Yangtze-Huaihe River basin where it is generally cultivated in late fall or winter [1]. Although a cool climate is the best growing environment for wucai, its growth is also at risk of cold stress at unusually lower temperatures, which inhibits its normal growth. Genotypes respond differently to cold, with some exhibiting a certain degree of tolerance, while others are extremely sensitive [2]. With increasingly more land being used for wucai cultivation every year, the selection of cold-resistant varieties has become a key research topic of interest in wucai plant breeding. Finding an efficient and rapid method to reliably distinguish cold tolerance among many genotypes would let us identify those best suited for cultivation in areas that experience cold spells. Another crucial advantage would be the identification of parental material 
in advance in the breeding programs, so as to find out the wucai genotypes that are more chilling tolerant and ensuring higher yield per unit area.

Most selection procedures for cold-tolerant plant varieties are traditionally based on subjective visual scoring or yield in their target environment, but how to use a convenient and rapid selection technique in a controlled environment has since become the main focus when screening cold-tolerant genotype(s). Research on cold tolerance indicators for different crop species have revealed trait change in response to cold stress: for example, specific leaf area (SLA) and shoot growth rate were used to select cold-tolerant miscanthus genotypes [3]; stomatal limitation inhibition was used to screen for soybean cold-tolerant genotypes [2]; ascorbic acid and proline show the greatest variation between cold-tolerant and cold-sensitive chickpea genotypes [4]. By using suitable evaluation indicators of cold-tolerance in cotton seedlings of different genotypes, a mathematical evaluation model for cold tolerance screening could be established [5]. Nonetheless, these indicators and methods are inconvenient and too slow for use in the cold-tolerance screening of numerous species genotypes at once.

Photosynthesis is highly sensitive to cold damage and is a major process in plant metabolism [6,7]. Studies have shown that the main target of cold stress is located in the reaction center of Photosystem II (PSII) [8]. Recently, changes in the chlorophyll, OJIP transients, has been used to evaluate the extent of damage to the photosynthetic apparatus under several environmental stresses [9]. Many studies have used only the ratio of the variable to maximum chlorophyll a fluorescence $\left(\mathrm{F}_{\mathrm{V}} / \mathrm{F}_{\mathrm{M}}\right)$ as a parameter for screening for cold tolerance $[10,11]$. However, through later studies, a growing body of evidence indicated that $\mathrm{F}_{\mathrm{V}} / \mathrm{F}_{\mathrm{M}}$ is not sensitive to cold damage, nor is it useful in cold damage identification as a suitable parameter [12,13]. A way around this issue is to rely on PIabs: it is based on the absorption of light energy performance index, and is a multiparameter expression of light and performance indices. The PIabs takes into consideration the three main functional steps of photosynthetic activity by a PSII reaction center complex (RC), namely light energy absorption (ABS), excitation energy trap $\left(\mathrm{TR}_{0}\right)$, and conversion of excitation energy to electron transport $\left(\mathrm{ET}_{0}\right)$. The expression is PIabs $=\mathrm{RC} / \mathrm{ABS}$ - $\left[\mathrm{TR}_{0} / \mathrm{RC} /\left(1-\mathrm{TR}_{0} / \mathrm{RC}\right)\right] \bullet\left[\mathrm{ET}_{0} / \mathrm{RC} /\left(1-\mathrm{ET}_{0} / \mathrm{RC}\right)\right]$ [14]. Studies on soybean have indicated that PIabs is a very sensitive indicator of soybean dark low temperature stress [3]. In the case of wheat, photochemical activity measured as PIabs in standard cultivars after controlled cold acclimation or in early winter was in accordance with their freezing tolerance levels. Hume et al. [15] have demonstrated that dark cooling had a much lower effect on PIabs in cold tolerant genotype Maple Arrow than sensitive tropical genotype Java $29[16,17]$. This evidence suggested that the Plabs may be a suitable parameter for accessing the dark tolerance of a large number of genotypes.

Here, from a collection of 124 wucai genotypes, 20 were selected on the basis of PIabs, of which four were tested for their correlations with cold tolerance indicators and genetic identifications. We found that PIabs proved to be a useful novel and convenient measurement for this crucial crop, capable of revealing large differences in cold response among the tested wucai genotypes. We suggest PIabs would be sensitive enough to evaluate their responses so as to ultimately rank them according to cold tolerance.

\section{Materials and Methods}

\subsection{Plant Material}

A total of 124 wucai genotypes used in this study, including 66 from the Vegetable Genetics and Breeding Laboratory; 24 from the Institute of Vegetables and Flowers at the Chinese Academy of Agricultural Sciences; 34 from the Wanjiang Vegetable Industrial Technology Institute. All the materials were highly inbred lines. All the seeds were sown in a soil-less substrate (peat/vermiculite (volume $=2 / 1)$ ) with all established plants moved into a climate chamber and randomly arranged for each genotype. They were initially grown in warm conditions of $25 / 18{ }^{\circ} \mathrm{C}$ and $14 / 10$-h day /night cycles, and under 300 PAR (photosynthetic active radiation) in addition to natural illumination, which reached light intensity of $1000 \mu \mathrm{mol}$ photons $\mathrm{m}^{-2} \mathrm{~s}^{-1}$. The relative humidity was set to $75 \%$ 
(day/night). The plants used in the experiments were at the six-leaf stage of development; half of all the genotypes were moved into the field, and their PIabs were measured after the rosette stage was reached, 40 days later; the other half stayed in the climate chamber where the temperature was reduced to $6{ }^{\circ} \mathrm{C}(12 \mathrm{~h})$ and its PIabs was measured. A total of 20 genotypes-10 lower PIabs and 10 higher Plabs genotypes-passed the primary screening (Figure 1$)$ in the $6{ }^{\circ} \mathrm{C}(12 \mathrm{~h})$ climate chamber and the rosette stage in the field conditions, based on their respective PIabs (Table 1).

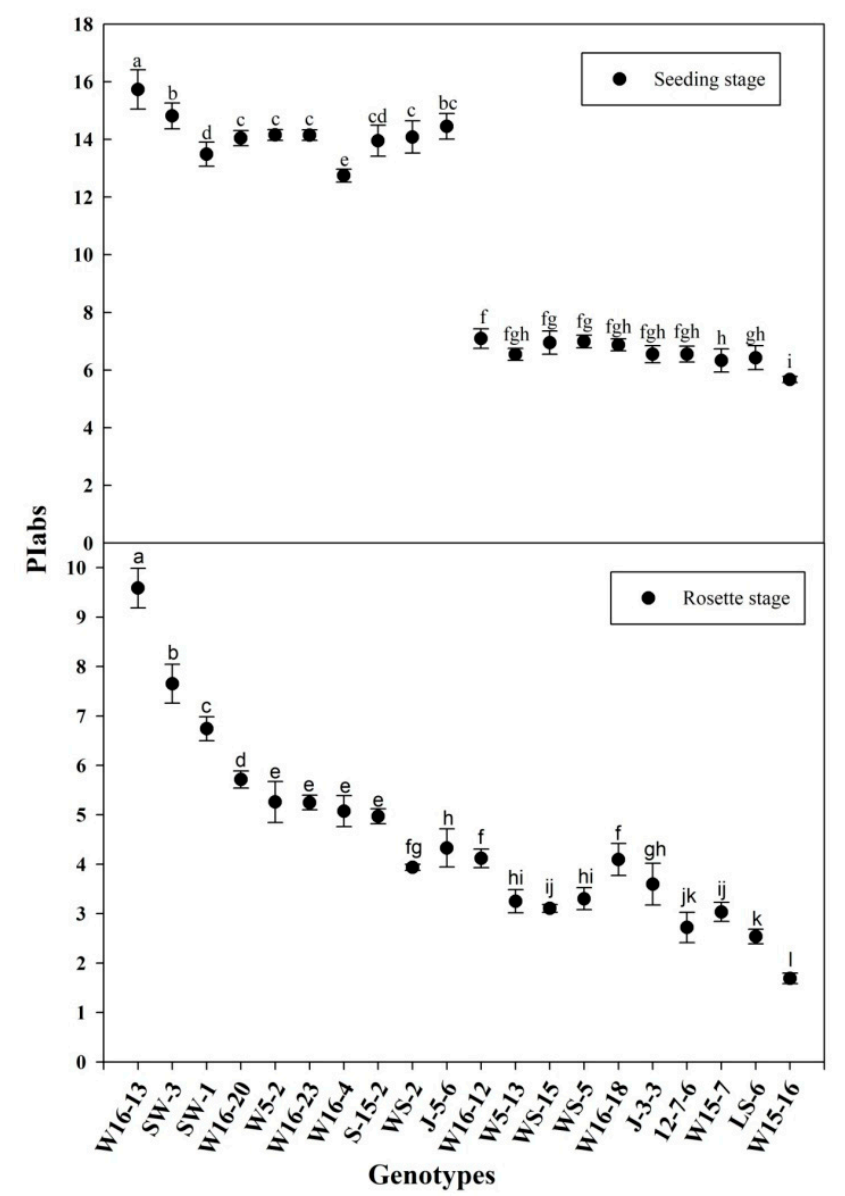

Figure 1. PIabs (seeding stage and rosette stage) of the selected genotypes. Error bars represent the SE $(n=3)$. Values with the same letter are not significantly different at the $p<0.05$.

These 20 genotypes of wucai were then replanted in the climate chamber. All conditions were the same as described above, but with a gradient of low temperature set for 8 days $\left(25 / 18{ }^{\circ} \mathrm{C} \mathrm{d} / \mathrm{n}\right.$ to $5 / 0{ }^{\circ} \mathrm{C}$ $\mathrm{d} / \mathrm{n}$ ) applied to plants atthe six-leaf stage. The seedlings were sampled for the determination of net photosynthetic rate, electrolyte leakage, chilling injury index, specific leaf area, and malondialdehyde contents. These cold tolerance indicators showed a high correlation with PIabs, and the highest PIabs (W6-13 and SW-3) and the lowest PIabs (LS-6 and W15-16) were screened out among the 20 genotypes for further validation.

In order to further verify the cold tolerance of the four wucai genotypes, those at the six-leaf stage received the low temperature treatment as shown in Figure 2. Cont (control): $25 / 18^{\circ} \mathrm{C}(\mathrm{d} / \mathrm{n}$ ); ST (sixteen degrees centigrade treatment): $16 / 10^{\circ} \mathrm{C}(\mathrm{d} / \mathrm{n})$; ET (eight degrees centigrade treatment): $8 / 2{ }^{\circ} \mathrm{C}(\mathrm{d} / \mathrm{n})$; ZT (zero degrees centigrade treatment): $0 /-6{ }^{\circ} \mathrm{C}(\mathrm{d} / \mathrm{n})$. The low temperature treatments progressively decreased from $25 / 18{ }^{\circ} \mathrm{C}, 16 / 10{ }^{\circ} \mathrm{C}, 8 / 2{ }^{\circ} \mathrm{C}$ to $0 /-6^{\circ} \mathrm{C}$. Leaves were collected from each treatment in the cold gradient to determine the physiological and biochemistry responses of the wucai genotypes. Each step of the experiment was done independently, consisting of three replications with 
10 individual plants per replicate. Three individual plants from each replicate were randomly selected for biochemical analyses.

Table 1. Genotypes measured in the climate chamber experiments.

\begin{tabular}{cccccccc}
\hline No. & Identification & Species & Origin & No. & Identification & Species & Origin \\
\hline 1 & W16-13 & wucai-W16 & CH-AH-HF & 11 & W16-12 & wucai-W16 & CH-AH-HF \\
2 & SW-3 & wucai-SW & CH-AH-LA & 12 & W5-13 & wucai-W5 & CH-SX \\
3 & SW-1 & wucai-SW & CH-AH-LA & 13 & WS-15 & wucai-WS & CH-AH-HN \\
4 & W16-20 & wucai-W16 & CH-AH-HF & 14 & WS-5 & wucai-WS & CH-AH-HN \\
5 & W5-2 & wucai-W5 & CH-SX & 15 & W16-18 & wucai-W16 & CH-AH-HF \\
6 & W16-23 & wucai-W16 & CH-AH-HF & 16 & J-3-3 & wucai-J-3 & CH-JS-SQ \\
7 & W16-4 & wucai-W16 & CH-AH-HF & 17 & $12-7-6$ & wucai-12-7 & CH-HN-XY \\
8 & S-15-2 & wucai-S-15 & CH-SD & 18 & W15-7 & wucai-W15 & CH-AH-FY \\
9 & WS-2 & wucai-WS & CH-AH-HN & 19 & LS-6 & wucai-LS & CH-HB-LHK \\
10 & J-5-6 & wucai-J-5 & CH-JS-HA & 20 & W15-16 & wucai-W15 & CH-AH-FY \\
\hline
\end{tabular}

Abbreviations: CH-AH-HF-Hefei, Anhui, China; CH-AH-LA-Luan, Anhui, China; CH-AH-HN-Huainan, Anhui, China; CH-AH-FY—Fuyang, Anhui, China; CH-JS-HA-Huaian, Jiangsu, China; CH-JS-SQ-Suqian, Jiangsu, China; CH-HN-XY - Xinyang, Henan, China; CH-HB-LHK—Laohekou, Hubei, China; CH-SX—Shanxi, China; CH-SD-Shandong, China.

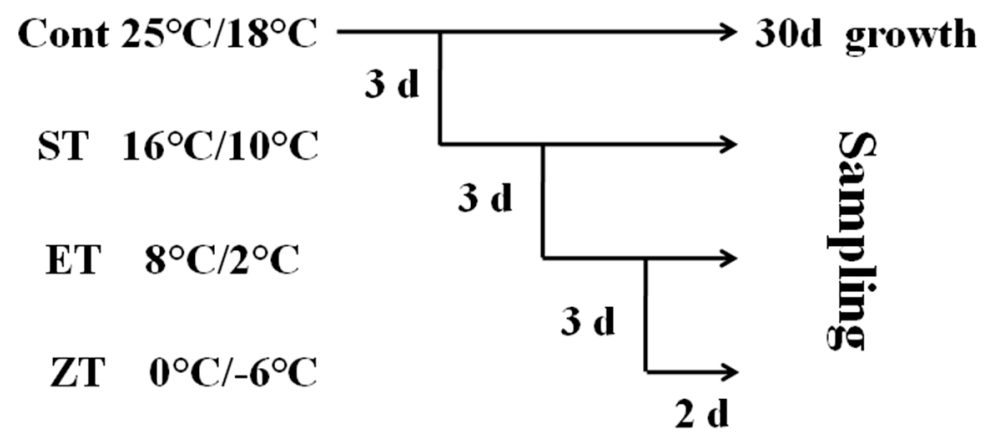

Figure 2. A schematic diagram of the low temperature treatment.

\subsection{Analysis of Net Photosynthetic Rate (Pn)}

Net photosynthetic rate was measured using the portable photosynthesis system (LI-6400, LI-COR Inc., Lincoln, NE, USA) in the third fully-expanded leaf of seedling. Three replicate measurements were taken per treatment on a clear day between 09:00 a.m. and 11:00 a.m. During these measurements, the environmental conditions were an $\mathrm{RH}$ of $75 \%$, external $\mathrm{CO}_{2}$ concentration of $380 \pm 10 \mu \mathrm{mol} \mathrm{mol}^{-1}$, and light intensity of $1000 \mu \mathrm{mol}$ photons $\mathrm{m}^{-2} \mathrm{~s}^{-1}$ [18].

\subsection{Measuring Electrolyte Leakage (EC)}

Electrolyte leakage was measured according to the method of Bajji et al. [19] with minor modifications. The leaves were perforated with a hole puncher with a radius of $5.5 \mathrm{~mm}$. Each disc was placed in a 20-mL tube containing $12 \mathrm{~mL}$ of deionized water and then shaken on a shaking table at $25{ }^{\circ} \mathrm{C}$ for $30 \mathrm{~min}$. At this time, the conductivity (EC1) of water was measured using a Thermo Orion STARA-HB conductivity meter (Thermo Orion., Waltham, MA, USA). The tube was heated in a boiling water bath for $30 \mathrm{~min}$, then cooled to room temperature, and the conductivity (EC2) was measured again. Final EC is expressed as the percentage of EC1/EC2.

\subsection{Determination of Chilling Injury Index (CII)}

Following Cao et al. [20], chilling injury scores were assigned to the wucai seedlings. Five score levels were used: 0 : leaves not withered; $1: 1 \% \sim 30 \%$ of leaves appear withered or shrunken; 2: $30 \% \sim 60 \%$ of leaves withered; $3: 60 \% \sim 90 \%$ of leaves withered; 4 : whole seedling wilted or dead. 
CII was equal to: $C I I=\Sigma X_{a} /(n \Sigma X)=\left(X_{1} a_{1}+X_{2} a_{2}+\ldots+X_{n} a_{n}\right) / n T$, where the number of seedlings with the same chilling level is indicated by $X_{n}$, and $a_{n}$ represents the chilling damage level.

\subsection{Determination of SLA}

The SLA was quantified using the method of Jiao et al. [3]. Using a puncher with a 110-mm diameter, 10 leaf discs with an area of $0.95 \mathrm{~cm}^{2}$ each were cut from the functional wucai leaves (normally the third and fourth leaf counting down from the top). These removed leaf discs were oven-dried at $85^{\circ} \mathrm{C}$ for 2 days and weighed. Their SLA was calculated as SLA = leaf area/leaf dry matter.

\subsection{Measurement of Malondialdehyde (MDA) Contents}

The MDA content was measured following $\mathrm{Hu}$ et al. [21] with some minor modifications. Specifically, $1 \mathrm{~g}$ of fresh leaves of wucai were ground in $10 \mathrm{~mL}$ of $10 \%$ trichloroacetic acid and centrifuged at $4000 \mathrm{r} / \mathrm{min}$ for $10 \mathrm{~min}$. Next, $2 \mathrm{~mL}$ of the extract after centrifugation was added to $2 \mathrm{~mL}$ of $0.6 \%$ thiobarbituric acid solution, and placed in a boiling water bath for $15 \mathrm{~min}$, rapidly cooled, and centrifuged. The supernatant was taken to measure its absorbance values at 532,600 , and $450 \mathrm{~nm}$. The MDA content was calculated: $\mathrm{C}_{\mathrm{MDA}}=6.45 \bullet\left(\mathrm{A}_{532}-\mathrm{A}_{600}\right)-0.56 \bullet \mathrm{A}_{450}\left(\mu \mathrm{mol} \mathrm{L}{ }^{-1}\right)$.

\subsection{Morphological Indexes}

Morphological indexes—includingplant height, stem diameter, individual plant weight, and dry weight-were obtained from 10 replicates per seedling. The plant height was measured from the cotyledonary node to the growing point with a ruler. The stem diameter was measured at the cotyledonary node using a vernier caliper. The fresh weight was measured after washing the plant with distilled water;and then dried in an oven at $75{ }^{\circ} \mathrm{C}$ for $72 \mathrm{~h}$, and the dry weight was measured.

\subsection{Chlorophyll Content}

The method for determining Chl was based on Zou et al. [22]. Fresh leaves $0.2 \mathrm{~g}$ (three replicates per treatment group) were taken and stored in $25 \mathrm{~mL}$ of acetone, ethanol and water (ratio of 4.5:4.5:1), and incubated for $24 \mathrm{~h}$ in a dark environment at $4{ }^{\circ} \mathrm{C}$. The absorbance at 649,665 , and $470 \mathrm{~nm}$ was measured after filtration. Chl concentration was calculated with this formula: Chla $=13.95 \bullet$ A665 6.88 • A649; Chlb = 24.96 • A649 - 7.32 • A665; Chla + b = Chla + Chlb; Car $=\left(1000 \bullet \mathrm{A}_{470}-2.05 \bullet\right.$ $\mathrm{Chl} a-114.8 \bullet \mathrm{Chl} b) / 245$.

\subsection{Total Antioxidant Capacity(T-AOC)}

T-AOC was measured via the colorimetric method using a kit (BC1310, Beijing Solarbia Science \& Technology Co., Ltd., Beijing, China). Under acidic conditions, the ability to reduce $\mathrm{Fe}^{3+}$-TPTZ to produce blue $\mathrm{Fe}^{2+}$-TPTZ corresponds to total antioxidant capacity. A 0.1-g subsample of fresh leaves was added to $1 \mathrm{~mL}$ of the pre-cooled extract for grinding, and the homogenate was centrifuged at $10,000 \mathrm{r} / \mathrm{min}$ for $5 \mathrm{~min}$ at $4{ }^{\circ} \mathrm{C}$. The supernatant was taken, and its absorbance was measured at a wavelength of $593 \mathrm{~nm}$. T-AOC activity was calculated as follows: T-AOC $(\mathrm{U} / \mathrm{g})=(34 \bullet \mathrm{X}) / \mathrm{W}$, where X is the $\mathrm{Fe}^{2+}$ concentration based on the standard curve and $\mathrm{W}$ is the subsample's mass.

\subsection{Measurement of OJIP Transients}

OJIP transients were measured after $25 / 18^{\circ} \mathrm{C}(\mathrm{d} / \mathrm{n})$ and $8 / 2^{\circ} \mathrm{C}(\mathrm{d} / \mathrm{n})$ of wucai seedlings' exposure to the low temperatures. Their leaves were dark-adapted for $30 \mathrm{~min}$ by special clips before any measurement. The OJIP transients were measured using a continuous excitation fluorometer Pocket PEA (Plant Efficiency Analyzer, Hansatech, King's Lynn, UK). 


\subsection{Leaf Cell Ultrastructure}

Ultramicroscopic sections of leaf cells were observed by microscopy. The leaves were cut into small 1-mm ${ }^{2}$ pieces and transferred into a glutaraldehyde fixative and fixed overnight at $4{ }^{\circ} \mathrm{C}$. After dehydration in acetone and embedding in Durcupan ACM (Fluka), ultrathin sections were cut on an ultramicrotome and stained with uranyl acetate and lead citrate. Embedded sections were observed under a transmission electron microscope (H-7650, Hitachi, Tokyo, Japan) at an accelerating voltage of $80 \mathrm{kV}$.

\subsection{Gene Expression}

To gain insight into the differences in cold tolerance between wucai varieties, genes conferring cold resistance traits, namely three cold related genes (ICE1, CBF1, CBF2) and two apolipoprotein genes (TIL, CHL), were assessed after finishing the low temperature treatments.Total RNA was extracted using the RNAprep Pure Plant Kit (Tiangen, Beijing, China).First, the quality of purified RNA was measured by demonstrating an absorbance ratio (A260/A280) of 1.8-2.0 on a UV spectrophotometer.Then, the quality-assured RNA was used as template, with the synthesis of cDNA processed by a Takara PrimeScript RT reagent Kit (Takara, Okinawa, Japan). The Bio-Rad CFX96 Real-Time PCR Detection System (Bio-Rad, Hercules, CA, USA) was applied for the qPCR reactions, with amplifications performed with Takara SYBR Premix Ex TaqTM II (TliRNaseH Plus; Takara, Okinawa, Japan) in a total volume of $25 \mu \mathrm{L}$, using $8.5 \mu \mathrm{L}$ of $\mathrm{dH}_{2} \mathrm{O}, 12.5 \mu \mathrm{L}$ of SYBR Premix Ex Taq ${ }^{\mathrm{TM}} \mathrm{II}, 2 \mu \mathrm{L}$ of diluted cDNA, $1 \mu \mathrm{L}$ of forward primer $(10 \mu \mathrm{M})$, and $1 \mu \mathrm{L}$ of reverse primer $(10 \mu \mathrm{M})$. The actin gene served as an internal control for normalization of gene expression. Gene sequences were cloned and primers for each accordingly designed. Primers for the fragment amplification were as follows: BccrICE1: 5'-AGGTCTTGGCGTCGTCTG-3' and 5'-GCATCCCTTTCTTCTTCCG-3'; BccrCBF1: 5'-GCGTCACCCAATTTACAGA-3' and 5'-TTAGGAAAGTGCCGAGC-3'; BccrCBF2: 5'-GGTAGGAAGAAGTTTCGGGAGA-3' and 5'-AGTCGGCGAAGTTGAGGC-3'; BccrTIL: 5'-ATGACGACCGAGAAGAAA-3' and 5'-TGGAAGGAAAGGAGGAAC-3'; BccrCHL: 5'-ATAGCCACAGACTACGACA-3' and 5'-TGAAGGGATCAAACTGGA-3'.

\subsection{Statistical Analysis}

All analyses were carried out in Microsoft Excel software and SPSS 19.0 software (SPSS, Chicago, CA, USA), using one-way analysis of variance of Duncan's multiple range testat the $p<0.05$ level of significance. Sigmaplot v10.0 (Systat Software Inc., San Jose, CA, USA) was used for plotting the results.

\section{Results}

\subsection{Relationships between Cold Tolerance Indexes and PIabs}

To determine the relationship between each cold tolerance index and PIabs, the 20 selected genotypes were subjected to an 8 -day gradient $\left(25 / 18{ }^{\circ} \mathrm{C} \mathrm{d} / \mathrm{n}\right.$ to $\left.5 / 0{ }^{\circ} \mathrm{C} \mathrm{d} / \mathrm{n}\right)$. We tested the associations among five cold tolerance indicators and PIabs (Tables 2 and 3) to further screen the genotypes. PIabs had a significant positive correlation with Pn and SLA (Figures 3 and 4), but its correlation with EC, MDA, and CII were significantly negative (Figures 5-7). This step suggested that PIabs were associated with these cold-tolerant indicators, but whether the genotypes selected using PIabs values are in fact cold-tolerant required further verification. To do this, among the 20 genotypes, the highest PIabs (W6-13 and SW-3) and lowest PIabs (LS-6 and W15-16) were deemed representative of higher and lower cold tolerance traits, respectively, by the selection. 
Table 2. Correlations among (PIabs, net photosynthetic rate, electrolyte leakage, specific leaf area, malondialdehyde) of 20 genotypes measured at $25 / 18^{\circ} \mathrm{C} \mathrm{d} / \mathrm{n}$.

\begin{tabular}{cccccc}
\hline Index & PIabs & Pn & EC & SLA & MDA \\
\hline PIabs & 1 & & & & \\
Pn & $0.9074^{* *}$ & 1 & & & \\
EC & $-0.8895^{* *}$ & $-0.8208^{* *}$ & 1 & 1 & \\
SLA & $0.8363^{* *}$ & $0.8072^{* *}$ & $-0.7453^{* *}$ & $-0.818^{* *}$ & 1 \\
MDA & $-0.9322^{* *}$ & $-0.8562^{* *}$ & $0.8262^{* *}$ & $-0.047{ }^{*}$
\end{tabular}

Note: Performance index on an absorption basis (Plabs); Net Photosynthetic Rate (Pn); Electrolyte Leakage (EC); Specific leaf area (SLA); Malondialdehyde (MDA). ${ }^{* *}$ means significant difference at $p<0.01$.

Table 3. Correlations among (PIabs, net photosynthetic rate, electrolyte leakage, specific leaf area, malondialdehyde, chilling index) of 20 genotypes measured at $5 / 0{ }^{\circ} \mathrm{C} \mathrm{d} / \mathrm{n}$.

\begin{tabular}{ccccccc}
\hline Index & PIabs & Pn & EC & SLA & MDA & CII \\
\hline PIabs & 1 & & & & & \\
Pn & $0.8561^{* *}$ & 1 & & & & \\
EC & $-0.8875^{* *}$ & $-0.7166^{* *}$ & 1 & & & \\
SLA & $0.8902^{* *}$ & $0.7149^{* *}$ & $-0.8738^{* *}$ & 1 & & \\
MDA & $-0.9317^{* *}$ & $-0.7378^{* *}$ & $0.9596^{* *}$ & $-0.8682^{* *}$ & 1 & \\
CII & $-0.921^{* *}$ & $-0.7502^{* *}$ & $0.8841^{* *}$ & $-0.8487^{* *}$ & $0.91322^{* *}$ & 1 \\
\hline
\end{tabular}

Note: Performance index on an absorption basis (PIabs); Net Photosynthetic Rate (Pn); Electrolyte Leakage (EC); Specific leaf area (SLA); Malondialdehyde (MDA); Chilling Injury Index (CII). ${ }^{* *}$ means significant difference at $p<0.01$.
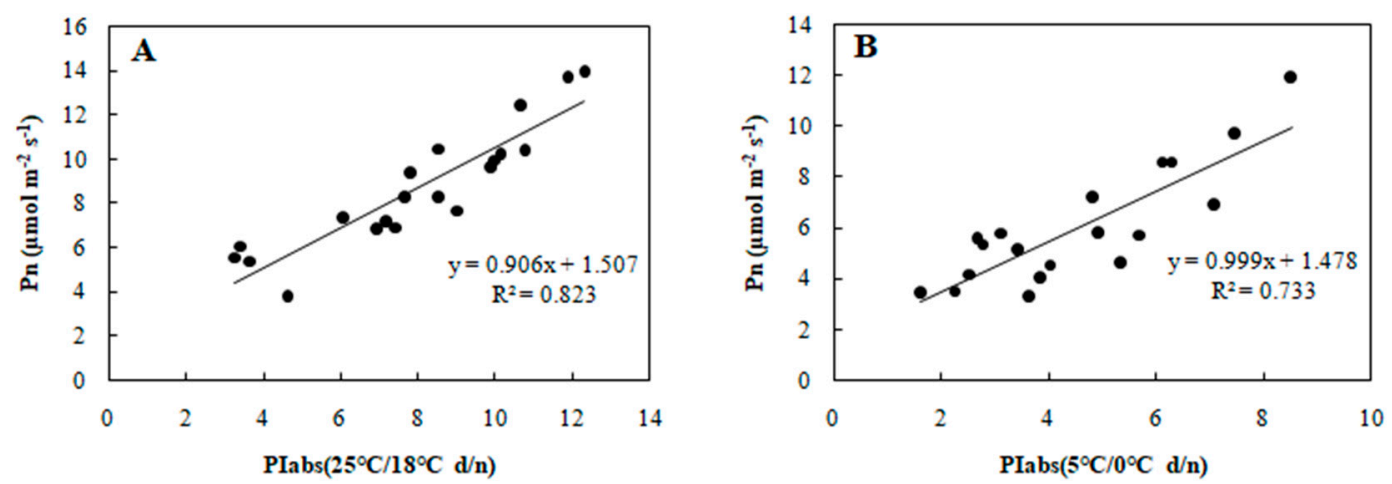

Figure 3. Correlation between PIabs and Pn in 20 wucai genotypes measured in (A) $25 / 18^{\circ} \mathrm{C}(\mathrm{d} / \mathrm{n})$ treatment and $(\mathbf{B}) 5 / 0{ }^{\circ} \mathrm{C}(\mathrm{d} / \mathrm{n})$ treatment.
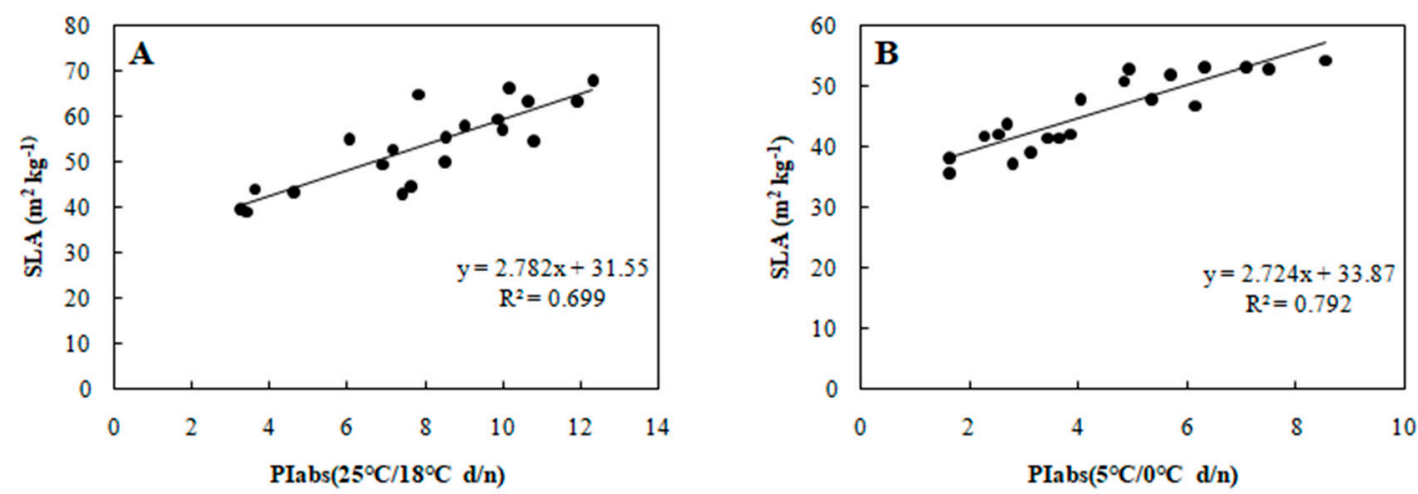

Figure 4. Correlation between PIabs and SLA in 20 wucai genotypes measured in $(\mathbf{A}) 25 / 18{ }^{\circ} \mathrm{C}(\mathrm{d} / \mathrm{n})$ treatment and $(\mathbf{B}) 5 / 0{ }^{\circ} \mathrm{C}(\mathrm{d} / \mathrm{n})$ treatment. 

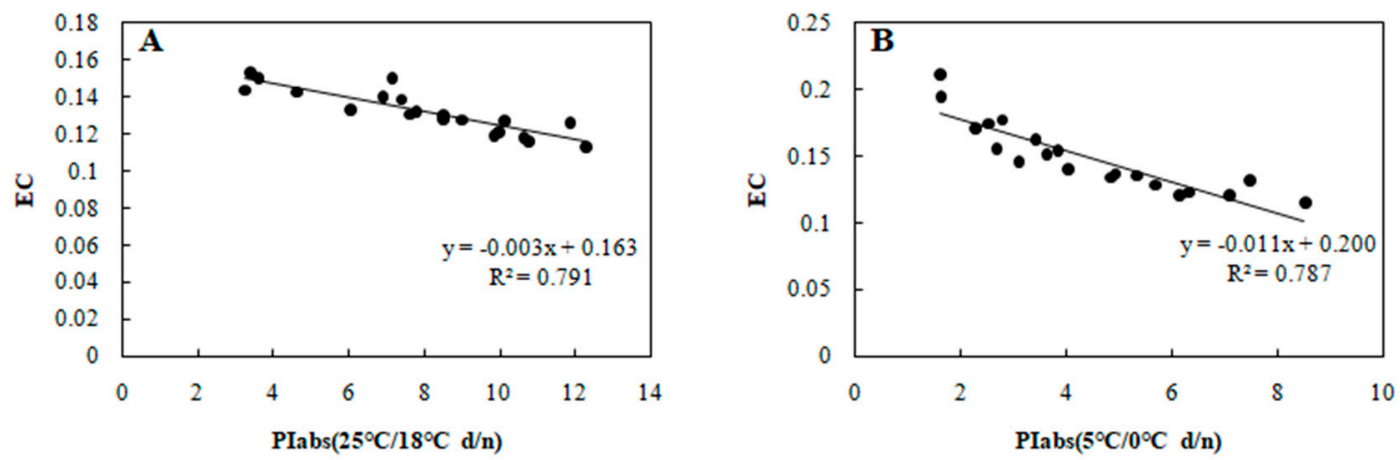

Figure 5. Correlation between PIabs and EC in 20 wucai genotypes measured in (A) $25 / 18{ }^{\circ} \mathrm{C}(\mathrm{d} / \mathrm{n})$ treatment and (B) $5 / 0{ }^{\circ} \mathrm{C}(\mathrm{d} / \mathrm{n})$ treatment.
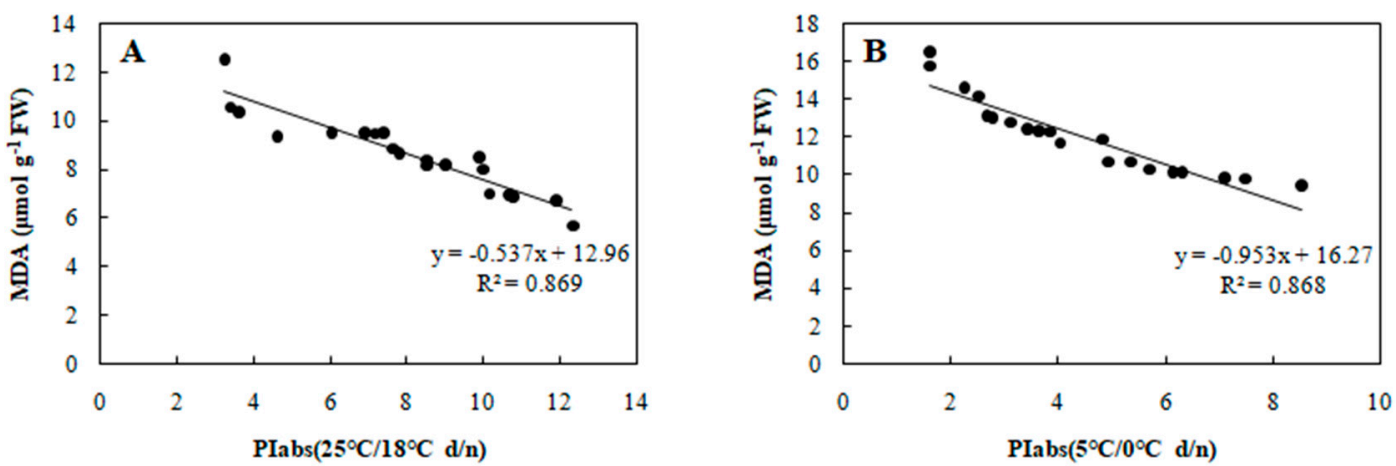

Figure 6. Correlation between PIabs and MDA in 20 wucai genotypes measured in $(A) 25 / 18{ }^{\circ} \mathrm{C}(\mathrm{d} / \mathrm{n})$ treatment and (B) $5 / 0^{\circ} \mathrm{C}(\mathrm{d} / \mathrm{n})$ treatment.

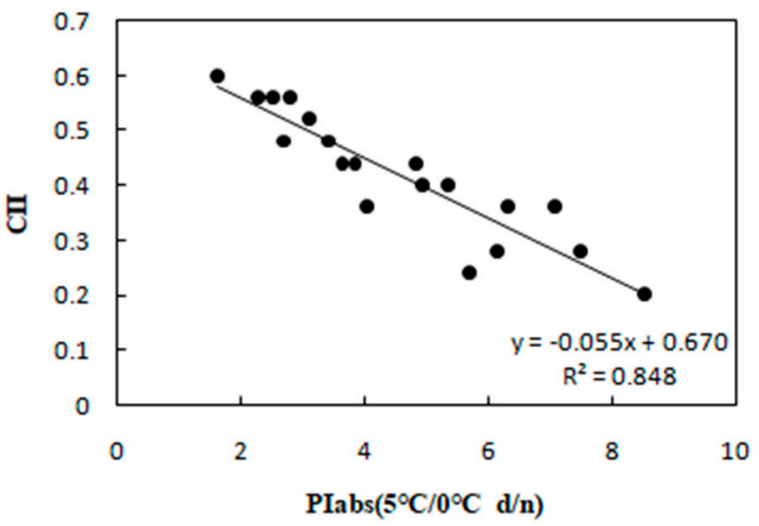

Figure 7. Correlation between PIabs and CII in 20 wucai genotypes measured in $5 / 0^{\circ} \mathrm{C}(\mathrm{d} / \mathrm{n})$ treatment.

\subsection{Morphological Indexes}

As shown in Table 4, plant heights of these four genotypes increased gradually with decreasing temperature; W16-13 and SW-3 (higher PIabs) showed increases of 7.16\% and 7.31\%, while LS-6 and W15-16 (lower PIabs) had increases of $9.60 \%$ and $8.95 \%$. Compared to their respective controls, the single plant weight and single plant dry plant weight of W16-13 and SW-3 were significantly reduced by $5.78 \%, 5.75 \%$ and $14.23 \%, 11.67 \%$ under cold stress, respectively; the above indexes were likewise decreased by $19.95 \%, 16.25 \%$ and $29.58 \%, 30.52 \%$ in LS- 6 and W15-16. The extent of decline under cold stress found for LS-6 and W15-16 was higher than that W16-13 and SW-3. In contrast, the stem diameters four genotypes were not significantly decreased in response to cold stress. Figure 8 shows the variation in the response of the four genotypes of wucai seedlings exposed to low temperature stress. 
Table 4. Effects of cold stress on plant morphology in four genotypes.

\begin{tabular}{cccccc}
\hline Cultivar & Treatments & $\begin{array}{c}\text { Plant Height } \\
\mathbf{( c m})\end{array}$ & $\begin{array}{c}\text { Stem Diameter } \\
\mathbf{( m m})\end{array}$ & $\begin{array}{c}\text { Single Plant } \\
\text { Weight } \mathbf{( g )}\end{array}$ & $\begin{array}{c}\text { Single Plant } \\
\text { Dry Weight } \mathbf{( g )}\end{array}$ \\
\hline \multirow{5}{*}{ W16-13 } & Cont & $14.24 \pm 0.89 \mathrm{~d}$ & $10.15 \pm 0.40 \mathrm{a}$ & $8.616 \pm 0.911 \mathrm{c}$ & $1.182 \pm 0.141 \mathrm{~b}$ \\
& ST & $14.81 \pm 0.84 \mathrm{c}$ & $10.08 \pm 0.41 \mathrm{~b}$ & $9.900 \pm 1.008 \mathrm{a}$ & $1.244 \pm 0.130 \mathrm{a}$ \\
& ET & $15.11 \pm 0.94 \mathrm{~b}$ & $10.03 \pm 0.41 \mathrm{c}$ & $9.250 \pm 1.043 \mathrm{~b}$ & $1.165 \pm 0.148 \mathrm{~b}$ \\
& ZT & $15.26 \pm 0.93 \mathrm{a}$ & $9.97 \pm 0.40 \mathrm{~d}$ & $8.118 \pm 0.602 \mathrm{c}$ & $1.114 \pm 0.148 \mathrm{c}$ \\
SW-3 & Cont & $9.60 \pm 0.72 \mathrm{c}$ & $7.44 \pm 0.63 \mathrm{a}$ & $5.290 \pm 0.335 \mathrm{~b}$ & $0.634 \pm 0.040 \mathrm{~b}$ \\
& ST & $9.98 \pm 0.64 \mathrm{~b}$ & $7.40 \pm 0.61 \mathrm{~b}$ & $6.532 \pm 0.501 \mathrm{a}$ & $0.667 \pm 0.039 \mathrm{a}$ \\
& ET & $10.59 \pm 0.63 \mathrm{a}$ & $7.36 \pm 0.62 \mathrm{c}$ & $6.036 \pm 0.205 \mathrm{a}$ & $0.615 \pm 0.039 \mathrm{c}$ \\
& ZT & $10.71 \pm 0.62 \mathrm{a}$ & $7.32 \pm 0.62 \mathrm{~d}$ & $4.537 \pm 0.304 \mathrm{c}$ & $0.560 \pm 0.034 \mathrm{~d}$ \\
LS-6 & Cont & $8.02 \pm 0.37 \mathrm{c}$ & $6.22 \pm 0.26 \mathrm{a}$ & $6.079 \pm 0.257 \mathrm{~b}$ & $0.566 \pm 0.033 \mathrm{~b}$ \\
& ST & $8.27 \pm 0.22 \mathrm{~b}$ & $6.15 \pm 0.27 \mathrm{~b}$ & $6.944 \pm 0.241 \mathrm{a}$ & $0.593 \pm 0.029 \mathrm{a}$ \\
& ET & $8.70 \pm 0.15 \mathrm{a}$ & $6.08 \pm 0.28 \mathrm{c}$ & $5.931 \pm 0.208 \mathrm{c}$ & $0.535 \pm 0.030 \mathrm{c}$ \\
& ZT & $8.79 \pm 0.17 \mathrm{a}$ & $6.00 \pm 0.26 \mathrm{~d}$ & $4.866 \pm 0.230 \mathrm{~d}$ & $0.474 \pm 0.025 \mathrm{~d}$ \\
W15-16 & Cont & $6.48 \pm 0.15 \mathrm{c}$ & $4.42 \pm 0.08 \mathrm{a}$ & $4.152 \pm 0.178 \mathrm{~b}$ & $0.308 \pm 0.017 \mathrm{~b}$ \\
& ST & $6.61 \pm 0.13 \mathrm{~b}$ & $4.30 \pm 0.10 \mathrm{~b}$ & $5.084 \pm 0.139 \mathrm{a}$ & $0.336 \pm 0.017 \mathrm{a}$ \\
& ET & $6.99 \pm 0.10 \mathrm{a}$ & $4.24 \pm 0.11 \mathrm{c}$ & $3.711 \pm 0.499 \mathrm{~b}$ & $0.281 \pm 0.021 \mathrm{c}$ \\
& ZT & $7.06 \pm 0.09 \mathrm{a}$ & $4.20 \pm 0.11 \mathrm{~d}$ & $2.924 \pm 0.121 \mathrm{c}$ & $0.214 \pm 0.016 \mathrm{~d}$ \\
\hline
\end{tabular}

Values represent the mean SE $(n=10)$. Letters indicate significant differences at $p<0.05$ according to Duncan's multiple range tests. Cont: $25 / 18{ }^{\circ} \mathrm{C}(\mathrm{d} / \mathrm{n})$; ST: $16 / 10{ }^{\circ} \mathrm{C}(\mathrm{d} / \mathrm{n})$; ET: $8 / 2{ }^{\circ} \mathrm{C}(\mathrm{d} / \mathrm{n}) ;$ ZT: $0 /-6{ }^{\circ} \mathrm{C}(\mathrm{d} / \mathrm{n})$.

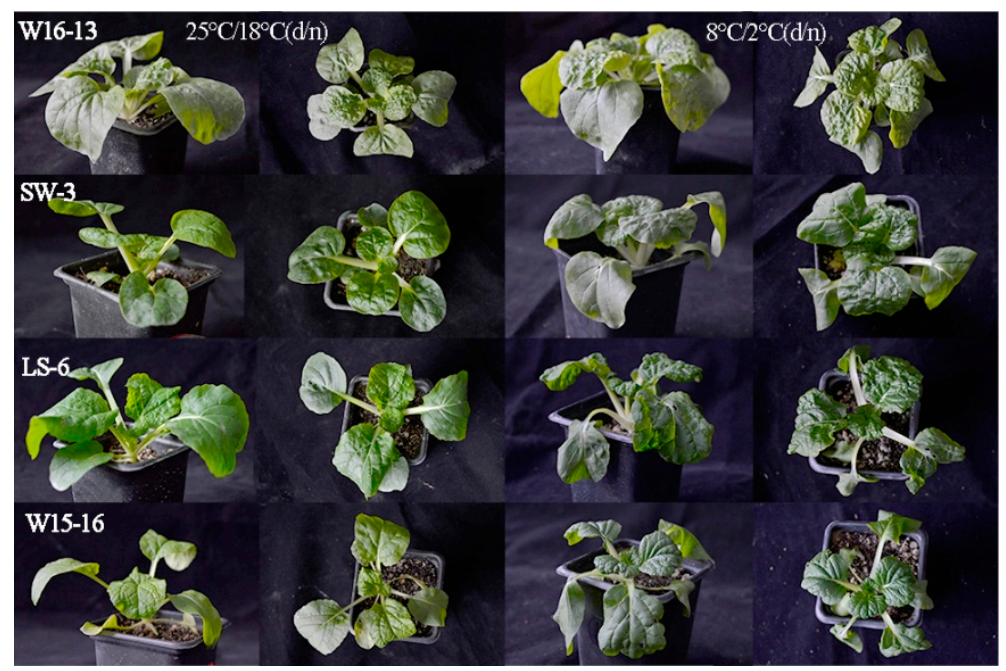

Figure 8. Variation in the response of four genotypes of wucai exposed to lowtemperature stress. Cont: $25 / 18{ }^{\circ} \mathrm{C}(\mathrm{d} / \mathrm{n}) ; \mathrm{ET}: 8 / 2{ }^{\circ} \mathrm{C}(\mathrm{d} / \mathrm{n})$.

\subsection{Chlorophyll Content}

Among the four wucai genotypes, their changes in $\mathrm{Chl} a, \mathrm{Chl} b, \mathrm{Chl} a+b$ and Car contents showed similar trends in response to cold stress. Both Chla and Chla+b gradually decreased under the four treatments, with those of LS- 6 and W15-16 significantly decreased at 8 and $0{ }^{\circ} \mathrm{C}$ (Figure 9A,C). In contrast, $\mathrm{Chl} b$ increased first but then decreased under all treatments, yet the change in $\mathrm{Chl} b$ contents of W16-13 and SW-3 were smaller than those of LS-6 and W15-16 (Figure 9B). The Car contents gradually increased, with those of LS-6 and W15-16 showing much greater changes than either W16-13 or SW-6 (Figure 9D). 


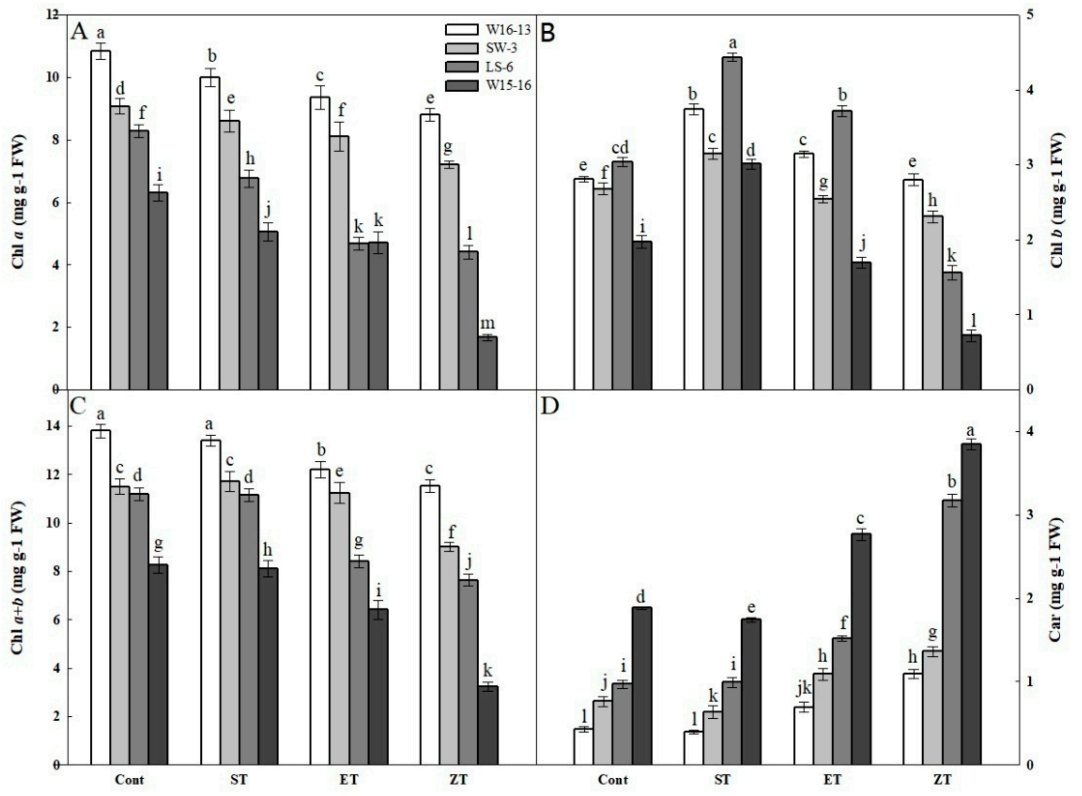

Figure 9. Effects of cold stress on (A) Chla, (B) Chlb, (C) Chla+b, (D) Car in four wucai genotypes. Values represent the mean SE $(n=3)$. Values with the same letter are not significantly different at the $p<0.05$. Cont: $25 / 18{ }^{\circ} \mathrm{C}(\mathrm{d} / \mathrm{n})$; ST: $16 / 10{ }^{\circ} \mathrm{C}(\mathrm{d} / \mathrm{n})$; ET: $8 / 2{ }^{\circ} \mathrm{C}(\mathrm{d} / \mathrm{n})$; ZT: $0 /-6{ }^{\circ} \mathrm{C}(\mathrm{d} / \mathrm{n})$.

\subsection{OJIP Curves of Cold Stress}

The so-called OJIP was used to analyze chlorophyll fluorescence transient. $\mathrm{F}_{\mathrm{m}}$ was the maximum fluorescence intensity; $\mathrm{F}_{0}$ was regarded as the fluorescence intensity at $50 \mathrm{~s} ; \mathrm{Ft}$ was the fluorescence intensity at any time point. $\mathrm{O}, \mathrm{J}, \mathrm{I}$, and $\mathrm{P}$ were different phases of the OJIP curve, representing the time to reach the maximum fluorescence intensity at $0.05,0.30,2.00$, and $30.00 \mathrm{~ms}$, respectively [23]. Fluorescence intensity $(\mathrm{Ft})$ at $25 / 18^{\circ} \mathrm{C}(\mathrm{d} / \mathrm{n})$ and $8 / 2{ }^{\circ} \mathrm{C}(\mathrm{d} / \mathrm{n})$ was normalized according to the formula $\left(\mathrm{F}_{\mathrm{t}}-\mathrm{F}_{0}\right) /\left(\mathrm{F}_{\mathrm{m}}-\mathrm{F}_{0}\right)$, and the OJIP standard curve was plotted (Figure 10A,C). The four genotypes had typical chlorophyll rapid fluorescence kinetic curves, including the phase points of $\mathrm{O}, \mathrm{J}, \mathrm{I}$, P.Their curves were similar in shape, and the time to reach the $\mathrm{P}$ phase was consistent among them.

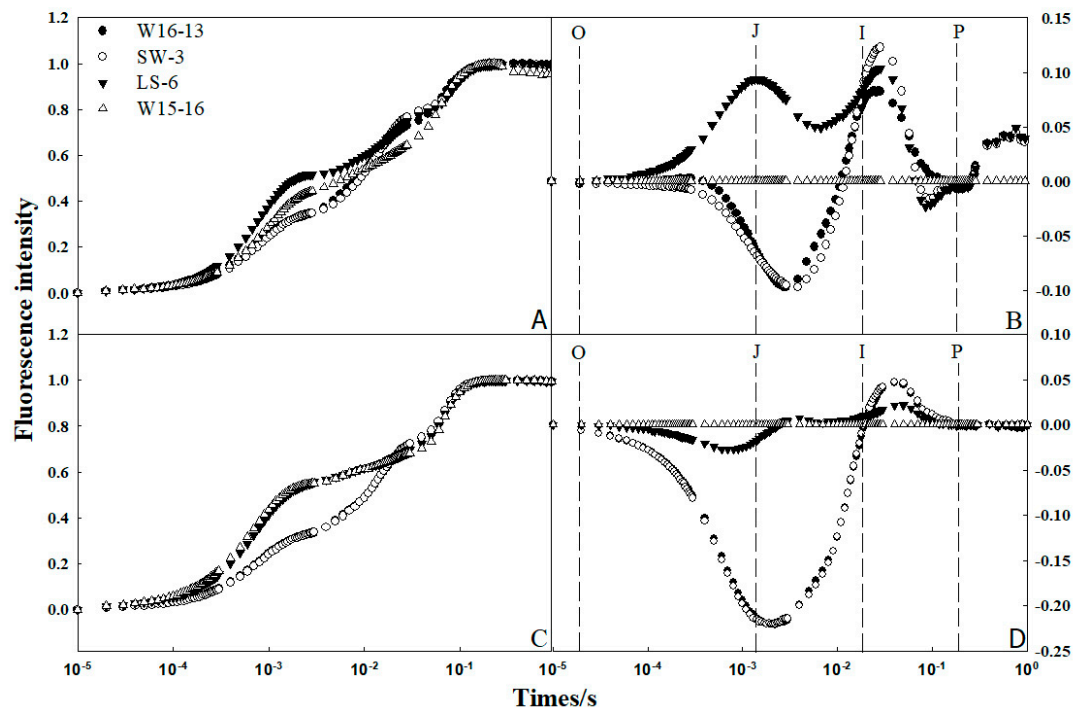

Figure 10. Effect of low temperature on the fluorescence transient of four genotypes of wucai. OJIP transients were measured after $25 / 18{ }^{\circ} \mathrm{C}(\mathrm{d} / \mathrm{n})(\mathbf{A}, \mathbf{B})$ and $8 / 2{ }^{\circ} \mathrm{C}(\mathrm{d} / \mathrm{n})(\mathbf{C}, \mathbf{D})$ of exposure to low temperatures. 
To determine possible differences in the fluorescence signal intensity between varieties before and after low temperature treatments, W15-16 was chosen as a control, and the standardized fluorescence interpolation between the other three varieties and W15-16 was redrawn (Figure 10B,D). This revealed that the fluorescence difference between varieties mainly arose between the J phase ( $2 \mathrm{~ms})$ and I phase (30 ms), with the difference near the former being largest. The fluorescence signals of LS- 6 and W15-16 were strong while those of W16-13 and SW-3 were small.

\subsection{Total Antioxidant Capacity}

The T-AOC of the four genotypes showed a similar pattern of change under each of the cold treatments (Figure 11). The $16^{\circ} \mathrm{C}$ cold stress treatment significantly enhanced the T-AOC of all genotypes, which was consistently highest among the four treatments. However, the range of increased and decreased T-AOC was significantly greater in W16-13 than the other three genotypes. Compared with the Cont values, the T-AOC of W16-13, SW-3, LS-6, and W15-16 had all declined by $10.15 \%$, $13.74 \%, 33.70 \%$, and $29.51 \%$ in ZT.

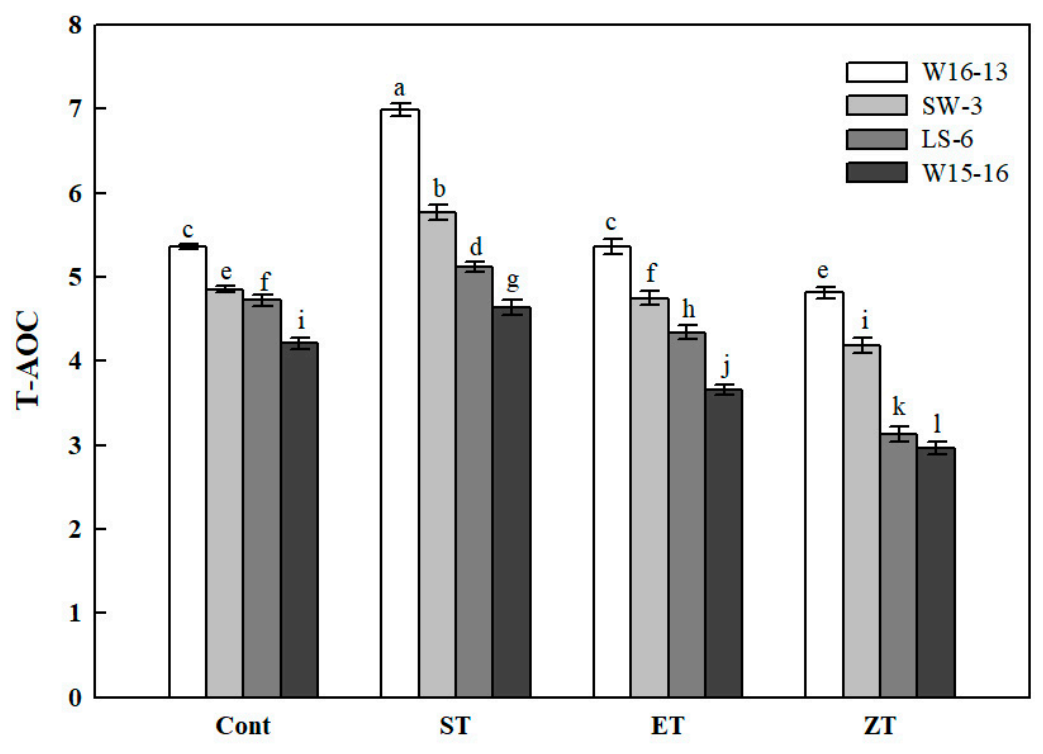

Figure 11. Effects of cold stress on total antioxidant capacity (T-AOC) in four wucai genotypes. Values represent the mean SE $(n=3)$. Values with the same letter are not significantly different at the $p<0.05$. Cont: $25 / 18^{\circ} \mathrm{C}(\mathrm{d} / \mathrm{n})$; ST: $16 / 10{ }^{\circ} \mathrm{C}(\mathrm{d} / \mathrm{n}) ; \mathrm{ET}: 8 / 2{ }^{\circ} \mathrm{C}(\mathrm{d} / \mathrm{n}) ; \mathrm{ZT}: 0 /-6{ }^{\circ} \mathrm{C}(\mathrm{d} / \mathrm{n})$.

\subsection{Leaf Cell Ultrastructure}

Mesophyll cell ultrastructure for the genotypes exposed to cold in ZT differed from those kept at the control temperatures. In Figures 6 and 7, the panels A, B, C, and D represent sections from control genotypes and panels E, F, G, and $\mathrm{H}$ represent sections from chilled genotypes. The extent of change varied between the four genotypes after four stagesof cold stress (Figure 12). The cytosol occupied a far greater proportion of the cytoplasm in mesophyll cells in the controls relative to the cold-treated genotypes. This discrepancy could be largely explained by the increased chloroplast size in those plants exposed to chilling (Figure 12G,H compared to C,D).

LS-6 and W15-16 chloroplasts were dilated and round after cold stress, while chloroplasts of W16-13 and SW-3 showed little change. While most chloroplast profiles in the controls were predominantly plano-convex over the experiment's time course, those from chilled plants were rounder and larger (Figure 13). Some large starch grains and few osmiophilic granules were scattered in the generally and chilled plants chloroplasts.In the chloroplast profiles of controls, most of the cross-sectional area was occupied by stroma. In contrast to those, the chloroplasts from chilled plants were swollen, which appeared to restrict the stroma and grana (Figure 13G,H compared to C,D). 

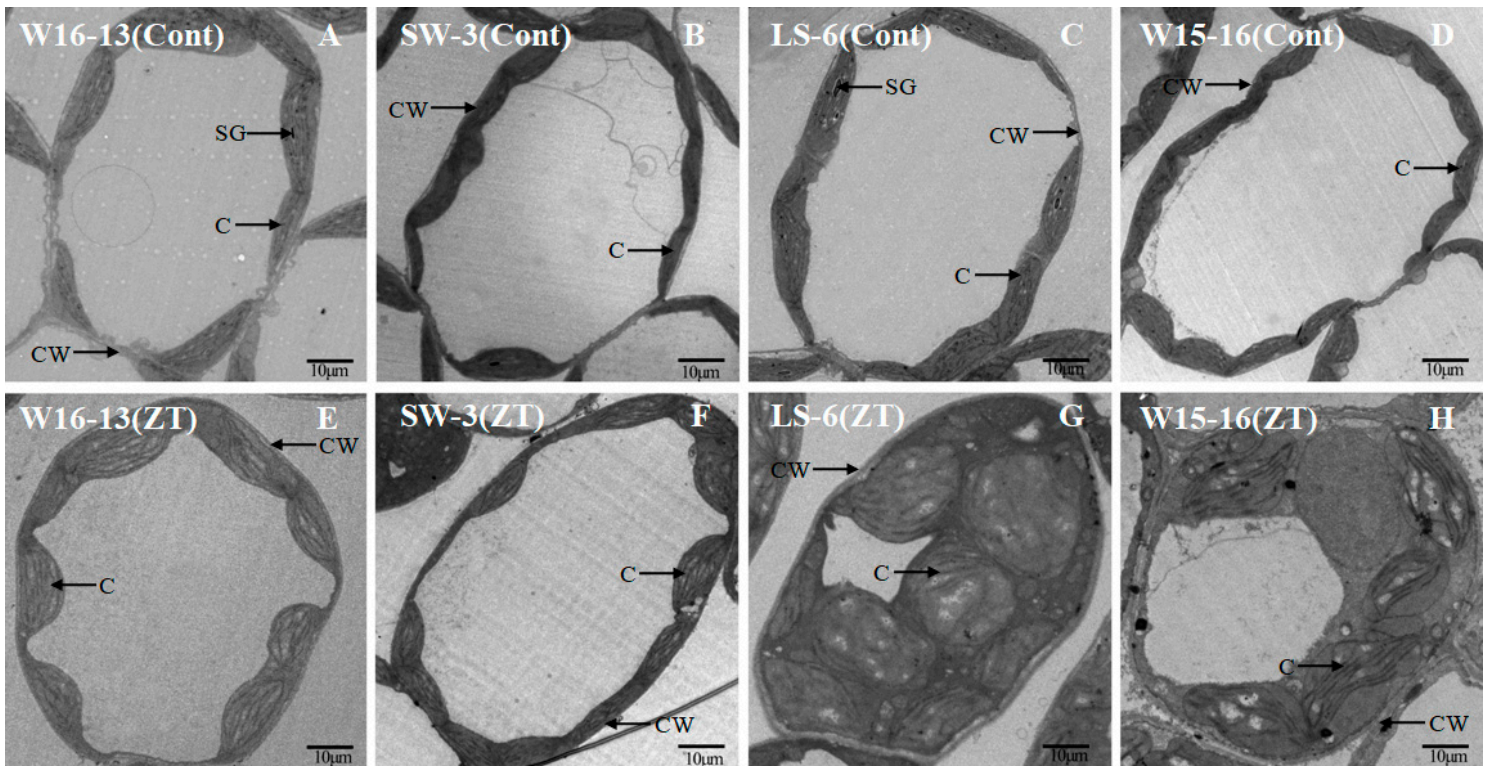

Figure 12. Transmission electron micrographs showing changes in ultrastructure of mesophyll cell of wucai seedlings under cold stress. Cont $\left[25 / 18{ }^{\circ} \mathrm{C}(\mathrm{d} / \mathrm{n})\right](\mathrm{A}-\mathrm{D}), \mathrm{ZT}\left[0 /-6{ }^{\circ} \mathrm{C}(\mathrm{d} / \mathrm{n})\right]$ stress treatment (E-H). CW: cell wall, SG: starch globule, C: chloroplast.
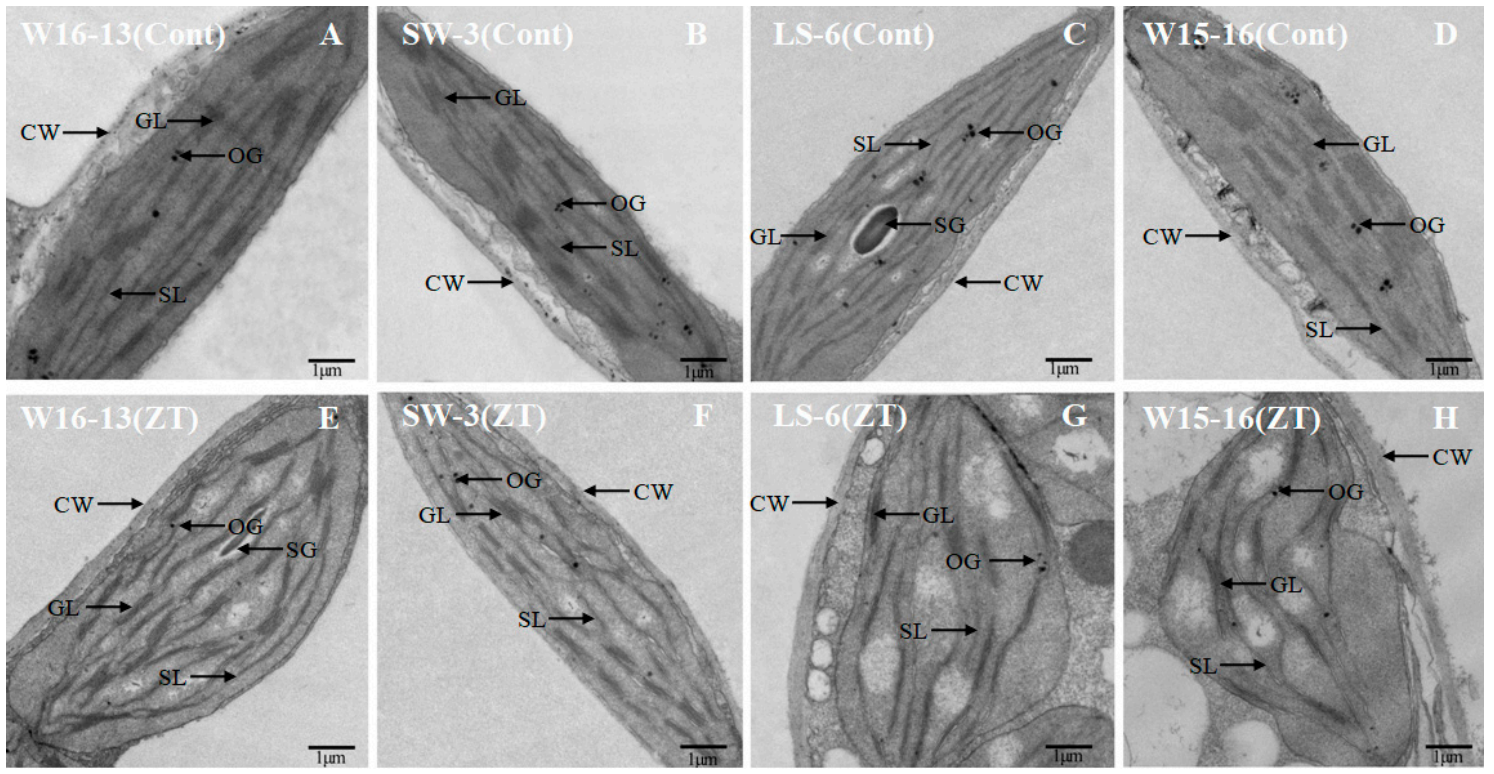

Figure 13. Transmission electron micrographs showing changes in ultrastructure of chloroplast of wucai seedlings under cold stress. Cont $\left[25 / 18^{\circ} \mathrm{C}(\mathrm{d} / \mathrm{n})\right](\mathbf{A}-\mathrm{D}), \mathrm{ZT}\left[0 /-6^{\circ} \mathrm{C}(\mathrm{d} / \mathrm{n})\right]$ stress treatment $(\mathrm{E}-\mathrm{H})$. SG: starch globule, GL: grana lamellae, SL: stroma lamellae, CW: cell wall, OG: osmiophilic granules.

\subsection{Changes in the Expression Levels of Cold-Related and Apolipoproteingenes}

Figure 14 shows the transcript levels of ICE1, CBF1, CBF2, TIL, CHL in leaves of the four wucai genotypes after low temperature in ET. Cold stress significantly affected the ICE1 and CHL genes' expression in LS-6 and W15-16, while TIL had a significantly higher expression level in W16-13 than in the other three genotypes of wucai. CBF1 and CBF2 were only significantly up-regulated in W16-13, while the expression levels of the other three wucai genotypes were all low and similar. 


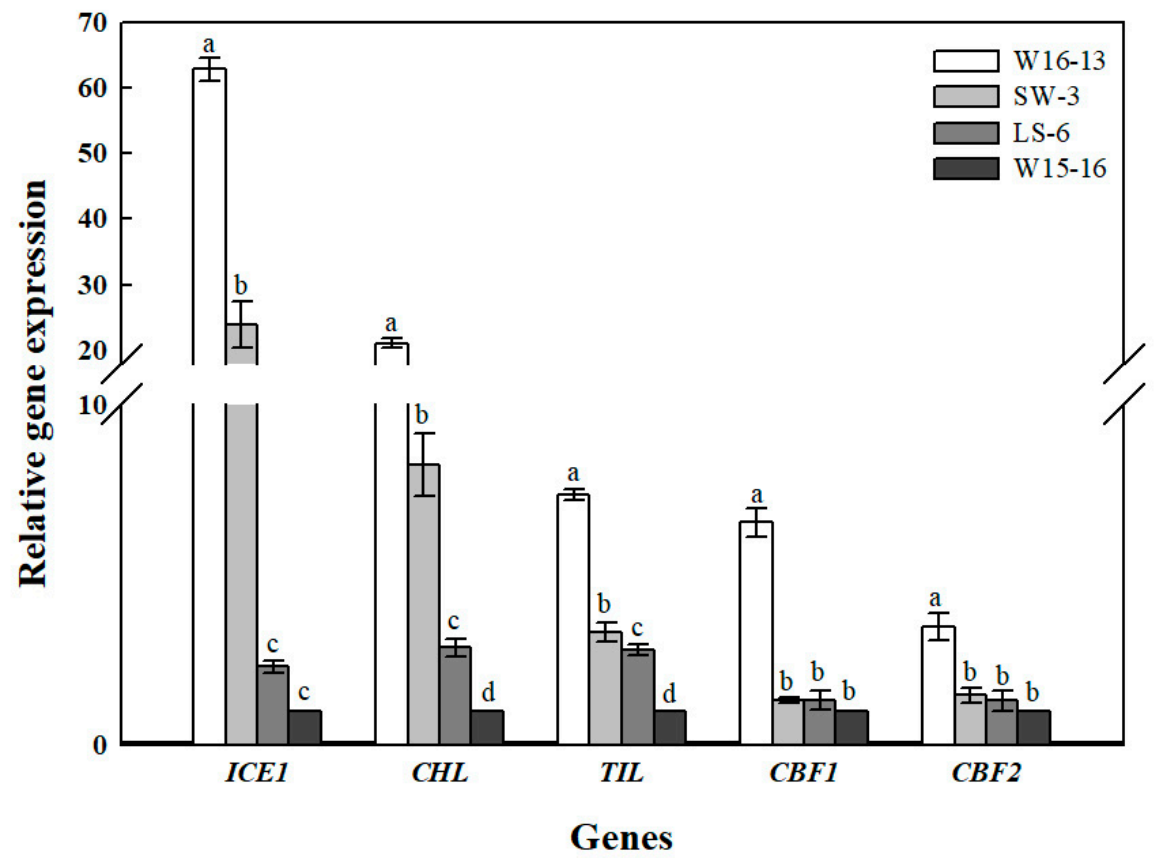

Figure 14. Gene expression analysis of cold stress wucai leaves in ET $\left[8 / 2{ }^{\circ} \mathrm{C}(\mathrm{d} / \mathrm{n})\right]$. Values represent the mean $\pm \operatorname{SE}(n=3)$. Values with the same letter are not significantly different at the $p<0.05$.

\section{Discussion}

Many plant species that establish, grow and reproduce in low temperature environments exhibit various adaptive strategies to cold stress in terms of their physiology, ecology, and morphology. Since photosynthesis is a temperature-sensitive physiological process in plants [24], a better understanding of its adaptive mechanism at low temperatures is crucial to increase crops' productivity and sustainability [25]. In our study, we found that wucai genotypes with a higher PIabs were capable of attaining higher photosynthetic efficiency than genotypes with a lower PIabs under cold stress, with a positive correlation between PIabs and Pn confirmed (Figure 3). Electrolyte leakage detection is an effective approach for estimating the cold tolerance of plants [26], but in such investigations the selection of an appropriate low temperature is crucial to accurately mirror the cold tolerance fluctuations in plants [27]. In our study, at either 25 or $5{ }^{\circ} \mathrm{C}$, the EC and PIabs were clearly negatively correlated (Figure 5). This indicated that PIabs could replace net photosynthetic rate or electrolyte leakage, to a certain extent, when making temperature sensitive measurements of crops.

Furthermore, SLA can also show a significant positive correlation with photosynthesis [28], and, as expected, PIabs and SLA were positively associated in our study (Figure 4). Cold stress is known to elevate MDA content in leaves [29], and we did find increased MDA that was negative correlated with PIabs (Figure 6). Currently, the CII is the most direct and reliable index by which to accurately gauge the degree of plant injury caused by chilling stress [16]. When plants suffer from this stress, physiological changes are the first response, which manifest as detectable visible symptoms of injury. The negative correlation between CII and PIabs (Figure 7) suggested that seedlings of the wucai genotype with higher PIabs were less prone to damage when cold. The above indexes-Pn, EC, SLA, MDA, CII—have been widely used in many plants in the field of cold tolerance research [30-34]. In our research, the relationship between PIabs and several indexes widely used in the cold research was chosen to improve the accuracy of predicting cold tolerance phenotypes.

This study's aim was to test the hypothesis that PIabs could be used to evaluate the cold tolerance of wucai plants. For this, we selected seedlings of four wucai genotypes differing in their PIabs sensitivity to cold stress: W16-13 and SW-3 (high-PIabs and cold-tolerant), LS-6 and W15-16 (low-PIabs and cold-sensitive). Low temperatures during early seedling growth is one of the most significant factors limiting in the lifetime productivity of plants [35]. In this study, two size 
variables of single plant weight and single plant dry plant weight were reduced significantly after the low temperature treatment (Table 4), confirming that seedling growth was strongly inhibited under cold stress conditions. Compared to their respective controls, plant heights of the four wucai genotypes increased gradually with decreasing temperature. Although low temperature markedly inhibited their biomass accumulation, the reductions in single fresh plant weight and dry weight in the high PIabs genotypes were clearly much smaller in magnitude than those occurring in low PIabs genotypes, despite them all having similarplant heights. This result strongly suggests higher PIabs wucai genotypes improve their ability to tolerate cold's adverse effects by regulating plant architectural traits.

The assembly and stability of the light-harvesting chlorophyll $a / b$ complex is indispensable for chlorophyll and carotenoids [36]. In this study, a more severe inhibition of Chl biosynthesis was found in wheat seedlings exposed to cold-stress versus heat-stress (e.g., Mohanty et al.) [37]. In this study, we found a decrease in Chl content at low temperature (Figure 9A-C). Compared to genotypes (W16-13 and SW-3) with high-PIabs, genotypes (LS-6 and W15-16) with low-PIabs showed a larger reduction in their leaf Chl. It had been reported that the species with lower content of Car are more resistant to low temperatures [38]. Indeed, from Figure 9D, both W16-13 and SW-3 showed lower levels of Car than did LS-6 and W15-16. These results suggest a change in Chl and Car contents at low temperatures may be caused by damaged chloroplast or by blocked pigment synthesis, leading to lower energy absorption capacity and lower photosynthetic capacity.

The OJIP transient is a sensitive and reliable method for detecting and quantifying cold stress in PSII [9]. The OJIP fluorescence transient reflects the filling up of the electron acceptor side of PSII ( $Q_{A}, Q_{B}$, and PQ pool) with electrons from the donor side of PSII [39,40], which can be used as a sensitive tool to investigate photosynthetic mechanisms in vivo. The shape of the OJIP fluorescence transient curve is very sensitive to various types of cold stress [41]. In our study, the OJIP curves decreased and /or increased under the $25 / 18^{\circ} \mathrm{C}(\mathrm{d} / \mathrm{n})$ and $8 / 2{ }^{\circ} \mathrm{C}(\mathrm{d} / \mathrm{n})$ of exposure to low temperatures. From Figure 10 we can draw two important inferences about the effect of cold stress on the OJIP fluorescence transients in leaves: (a) the shape of the OJIP fluorescence transients recorded under the $8 / 2{ }^{\circ} \mathrm{C}(\mathrm{d} / \mathrm{n})$ treatment of the four genotypes differed from that under the $25 / 18{ }^{\circ} \mathrm{C}(\mathrm{d} / \mathrm{n})$ untreated plants (Figure 10A,B compared to C,D); and (b) there were significant differences between the high- and low-PIabs genotypes regarding the extent to which the transient shape was altered by cold stress, particularly in its J-peak (2 ms) (Figure 10D). These results showed that the fluorescence signal of the lower PIabs genotypes (LS-6 and W15-16) had strong fluorescence signals, and the largest difference among the four genotypes appeared near the J phase. An increase in fluorescence intensity at $2 \mathrm{~ms}$ is usually interpreted as evidence for an accumulation in the fraction of the reduced $\mathrm{Q}_{\mathrm{A}}{ }^{-}$ pool, possibly due to diminished electron transport beyond $\mathrm{Q}_{\mathrm{A}}{ }^{-}$[42]. This result indicated that the high-PIabs genotypes had a PSII reaction center that dissipated less energy in the form of fluorescence than that of the low-PIabs genotypes.

As previously reported, variation between species and genotypes in tolerance to various environmental stresses are often related to the antioxidant capacity of their leaves [43]. Therefore, plant antioxidant capacity is a potentially useful marker of stress resistance phenotypes [44]. The antioxidant system in the four wucai genotypes was activated in response to cold stress (Figure 11), but not significantly so in the high-PIabs genotypes (W16-13 and SW-3). The ultrastructural morphological injuries were apparent in wucai leaves under cold stress, but these were altered to different degrees at $0{ }^{\circ} \mathrm{C}$. Chloroplasts is where most photosynthesis occurs, and it is the first and most serious organelle susceptible to cold injury [45]. The proportion of the cytoplasm in mesophyll cells was greatly reduced following the cold stress period (Figure 12), as temperatures just below freezing point-in the $0 /-6{ }^{\circ} \mathrm{C} \mathrm{d} / \mathrm{n}$ treatment-resulted in the development of swollen chloroplasts with disorganized lamella (Figure 13). These observations are similar to those of Murphy et al. [46]. Moreover, we found fewer visible changes in the cellular structure of high-PIabs genotypes (W16-13 and SW-3), coupled to some starch granules and osmiophilic granules added in the chloroplasts. However, dilation of 
thylakoids in the low-PIabs genotypes (LS-6 and W15-16) had already begun at $25 / 18^{\circ} \mathrm{C}(\mathrm{d} / \mathrm{n})$ chilling and was more pronounced at $0 /-6^{\circ} \mathrm{C}(\mathrm{d} / \mathrm{n})$. This indicated that the low-PIabs genotypes' chloroplast and thylakoid structures suffered from more damage than those in high-PIabs genotypes. Together, these results suggest high-PIabs genotypes had a more complete chloroplast or membrane structure, which was closely related to their higher antioxidant capacity.

The CBF pathway in plants is widely reportedly as activated under cold stress [47]. Overexpression of CBFs enhances osmolyte accumulation, reduces plants growth rates, and enhances abiotic stress tolerance [48]. In our study, expression levels of CBF1 and CBF2 in W16-13 exceeded those in other three wucai genotypes at $8 / 2{ }^{\circ} \mathrm{C}(\mathrm{d} / \mathrm{n})$ of low temperature conditions (Figure 14); however, SW-3 of the same high PIabs was not activated by low temperature nor regulated by CBF1 and CBF2, perhaps because the anti-cold nature of SW- 3 itself was not regulated by the $C B F$ gene. ICE1 is a positive regulator of $C B F 3$ and plays a key role in how Arabidopsis adapts to environmental changes [49]. Overexpression of ICE1 in cucumber induces expression of cold-induced genes, and it may trigger the accumulation of soluble sugars and free proline and slow the rate of MDA accumulation [50]. The elevated expression of ICE1 in the high-PIabs genotypes (W16-13 and SW-3) suggests these seedlings benefited from less electrolyte leakage and could better regulate their osmotic potential and osmotic stress under cold stress. Temperature-induced lipocalins (TIL) and chloroplastic lipocalins $(\mathrm{CHL})$ are plasmalemma-localized proteins also responsive to environmental stresses [51]. The role of TIL in tolerance to cold has been demonstrated in transgenic Arabidopsis overexpressing TIL [52]. Other studies have shown that chloroplastic lipocalin $(\mathrm{CHL})$ may perform a similar role in the protection of plastidial membranes during stress by interacting with chloroplast lipids [53]. We found that high-PIabs (W16-13 and SW-3) had the highest CHL expression under low temperature, but those of the low-PIabs genotypes (LS-6 and W15-16) and SW-3 had similar TIL expression, perhaps because the expression levels of TIL genes were not activated or very weak at low temperature.

\section{Conclusions}

In summary, we convincingly demonstrate that cold tolerance of 124 wucai genotypes greatly depends on genotypic variation. By measuring Plabs, net photosynthetic rate, electrolyte leakage, chilling injury index, specific leaf area, malondialdehyde content, we screened four wucai genotypes: W16-13 and SW-3 (high-PIabs) and LS-6 and W15-16 (low-PIabs), for which we then measured their morphological indexes, chlorophyll content, total antioxidant capacity, OJIP transients, leaf cell ultrastructure, and gene expression levels.During each phase of the cold gradient treatment period, PIabs was studied as new parameters, which made it possible to evaluate the cold sensitivity of each genotype during the entire period of cold stress. We determined the effect of cold stress on PIabs, finding it a very sensitive indicator of cold stress in wucai seedlings. Hence PIabs, which is easy to measure, could be used to quickly select individuals under field conditions for analysis or to screen wucai genotypes for enhanced cold tolerance.

Author Contributions: C.W., R.S. and L.Y. conceived and designed the experiments; Y.D. performed the experiments; J.W., S.X. and M.Z. analyzed the data; G.C. and S.Z. contributed reagents/materials/analysis tools; Y.D. wrote the paper.

Acknowledgments: This work was funded by National Natural Science Foundation of China (No. 31701910), National Key R \& D Program of China (2017YFD0101803), Major Science and Technology Projects of Anhui Province, China (17030701013). This work was performed at the Key Laboratory of Biology and Genetic Improvement of Horticultural Crops, Ministry of Agriculture, Beijing, China.

Conflicts of Interest: The authors declare no conflict of interest. 


\section{References}

1. Chen, G.; Ye, X.; Zhang, S.; Zhu, S.; Yuan, L.; Hou, J.; Wang, C. Comparative Transcriptome Analysis between Fertile and CMS Flower Buds in Wucai (Brassica campestris L.). BMC Genomics 2018, 19, 908. [CrossRef] [PubMed]

2. Heerden, P.D.R.V.; Viljoen, M.M.; Villiers, M.F.D.; Krüger, G.H.J. Limitation of photosynthetic carbon metabolism by dark chilling in temperate and tropical soybean genotypes. Plant Physiol. Biochem. 2004, 42, 117-124. [CrossRef]

3. Jiao, X.; Kørup, K.; Andersen, M.N.; Petersen, K.K.; Prade, T.; Jeżowski, S.; Ornatowski, S.; Górynowicz, B.; Spitz, I.; Lærke, P.E. Low-temperature leaf photosynthesis of a Miscanthus germplasm collection correlates positively to shoot growth rate and specific leaf area. Ann. Bot. 2016, 117, 1229-1239. [CrossRef] [PubMed]

4. Kumar, S.; Malik, J.; Thakur, P.; Kaistha, S.; Sharma, K.D.; Upadhyaya, H.D.; Berger, J.D.; Nayyar, H. Growth and metabolic responses of contrasting chickpea (Cicer arietinum L.) genotypes to chilling stress at reproductive phase. Acta Physiol. Plantarum. 2011, 33, 779-787. [CrossRef]

5. Wu, H.; Hou, L.L.; Zhou, Y.F.; Fan, Z.C.; Shi, J.Y.; Aliyan, R.; Zhang, J.S. Analysis of Chilling-Tolerance and Determination of Chilling-Tolerance Evaluation Indicators in Cotton of Different Genotypes. Sci. Agric. Sin. 2012, 45, 1703-1713.

6. Artuso, A.; Guidi, L.; Soldatini, G.F.; Pardossi, A.; Tognoni, F. The influence of chilling on photosynthesis and activities of some enzymes of sucrose metabolism in Lycopersicon esculentum Mill. Acta Physiol. Plantarum. 2000, 22, 95-101. [CrossRef]

7. Foyer, C.H.; Vanacker, H.; Gomez, L.D.; Harbinson, J. Regulation of photosynthesis and antioxidant metabolism in maize leaves at optimal and chilling temperatures: Review. Plant Physiol. Biochem. 2002, 40, 659-668. [CrossRef]

8. Kornyeyev, D.; Logan, B.P.; Allen, R.D.; Holaday, A.S. Enhanced photochemical light utilization and decreased chilling-inducedphotoinhibition of photosystem II in cotton overexpressing genes encodingchloroplast-targeted antioxidant enzymes. Physiol. Plant. 2010, 113, 323-331. [CrossRef]

9. Zushi, K.; Kajiwara, S.; Matsuzoe, N. Chlorophyll a fluorescence OJIP transient as a tool to characterize and evaluate response to heat and chilling stress in tomato leaf and fruit. Sci. Horticult. 2012, 148, 39-46. [CrossRef]

10. Bertin, P.; Kinet, J.M.; Bouharmont, J. Evaluation of chilling sensitivity in different rice varieties. Relationship between screening procedures applied during germination and vegetative growth. Euphytica 1996, 89, $201-210$. [CrossRef]

11. Meir, S.; Ronen, R.; Lurie, S.; Philosoph-Hadas, S. Assessment of chilling injury during storage: Chlorophyll fluorescence characteristics of chilling-susceptible and triazole-induced chilling tolerant basil leaves. Postharvest Biol. Technol. 1997, 10, 213-220. [CrossRef]

12. Dong, X.; Wang, Y.S.; Dou, G.R.; Hou, H.Y.; Shi, Y.Y.; Zhang, R.; Ma, K.; Wu, L.; Yao, L.B.; Cai, Y.; Zhang, J. Analysis of effect of Dll4 on the proliferation of RF/6A cells, co-cultured with RPE cells under hypoxia by MTT proliferation, assay. Acta Crystallogr. 2013, 55, 665-672.

13. Nikolic, P.N.; Borisev, K.M.; Pajevic, P.; Arsenov, D.; Zupunski, D.M.; Orlovic, S.; Pilipovic, R.A. Photosynthetic response and tolerance of three willow species to cadmium exposure in hydroponic culture. Arch. Biol. Sci. 2015, 67, 1411-1420. [CrossRef]

14. Strauss, A.J.; Krueger, G.H.J.; Strasser, R.J.; Van Heerden, P.D.R. Ranking of dark chilling tolerance in soybean genotypes probed by the chlorophyll a fluorescence transient O-J-I-P. Environ. Exp. Bot. 2006, 56, 147-157. [CrossRef]

15. Rapacz, M.; Sasal, M.; Kalaji, H.M.; Kościelniak, J. Is the OJIP Test a Reliable Indicator of Winter Hardiness and Freezing Tolerance of Common Wheat and Triticale under Variable Winter Environments. PLoS ONE 2015, 10, 0134820. [CrossRef] [PubMed]

16. Hume, D.J.; Jackson, A.K.H. Frost tolerance in soybeans. Cropence 1981, 21, 689-692.

17. Lawn, R.J.; Hume, D.J. Response of Tropical and Temperate Soybean Genotypes to Temperature During Early Reproductive Growth1. Crop Sci. 1985, 25, 137-142. [CrossRef]

18. Yuan, L.; Tang, L.; Zhu, S.; Hou, J.; Chen, G.; Liu, F.; Liu, S.; Wang, C. Influence of heat stress on leaf morphology and nitrogen-carbohydrate metabolisms in two wucai (Brassica campestris L.) genotypes. Acta Soc. Bot. Poloniae 2017, 86, 3554. [CrossRef] 
19. Bajji, M.; Kinet, J.M.; Lutts, S. The use of the electrolyte leakage method for assessing cell membrane stability as a water stress tolerance test in durum wheat. Plant Growth Regul. 2002, 36, 61-70. [CrossRef]

20. Cao, X.; Jiang, F.; Wang, X.; Zang, Y.; Wu, Z. Comprehensive evaluation and screening for chilling-tolerance in tomato lines at the seedling stage. Euphytica 2015, 205, 569-584. [CrossRef]

21. Hu, Z.; Weijian, L.; Yali, F.; Huiquan, L. Gibberellic acid enhances postharvest toon sprout tolerance to chilling stress by increasing the antioxidant capacity during the short-term cold storage. Sci. Horticult. 2018, 237, 184-191. [CrossRef]

22. Zou, M.; Yuan, L.; Zhu, S.; Liu, S.; Ge, J.; Wang, C. Effects of heat stress on photosynthetic characteristics and chloroplast ultrastructure of a heat-sensitive and heat-tolerant cultivar of wucai (Brassica campestris L.). Acta Physiol. Plant. 2017, 39, 30. [CrossRef]

23. Çiçek, N.; Oukarroum, A.; Strasser, R.J.; Schansker, G. Salt stress effects on the photosynthetic electron transport chain in two chickpea lines differing in their salt stress tolerance. Photosynth. Res. 2017, 136, 1-11. [CrossRef] [PubMed]

24. Li, X.; Ahammed, G.J.; Li, Z.; Zhang, L.; Wei, J.; Yan, P.; Zhang, L.; Han, W. Freezing stress deteriorates tea quality of new flush by inducing photosynthetic inhibition and oxidative stress in mature leaves. Sci. Horticult. 2018, 230, 155-160. [CrossRef]

25. Głowacka, K.; Adhikari, S.; Peng, J.H.; Gifford, J.; Juvik, J.A.; Long, S.P.; Sacks, E.J. Variation in chilling tolerance for photosynthesis and leaf extension growth among genotypes related to the $\mathrm{C}_{4}$ grass Miscanthus $\times$ giganteus. J. Exp. Bot. 2014, 65, 5267-5278. [CrossRef] [PubMed]

26. Armstrong, J.J.; Takebayashi, N.; Sformo, T.; Wolf, D. Cold tolerance in Arabidopsis kamchatica. Am. J. Bot. 2015, 102, 439-448. [CrossRef]

27. Hao, X.; Wang, B.; Wang, L.; Zeng, J.; Yang, Y.; Wang, X. Comprehensive transcriptome analysis reveals common and specific genes and pathways involved in cold acclimation and cold stress in tea plant leaves. Sci. Horticult. 2018, 240, 354-368. [CrossRef]

28. Dohleman, F.G.; Heaton, E.A.; Leakey, A.D.B.; Long, S.P. Does greater leaf-level photosynthesis explain the larger solar energy conversion efficiency of Miscanthus relative to switchgrass? Plant Cell Environ. 2009, 32, 1525-1537. [CrossRef] [PubMed]

29. Liu, A.; Hu, Z.; Bi, A.; Fan, J.; Gitau, M.M.; Amombo, E.; Chen, L.; Fu, J. Photosynthesis, antioxidant system and gene expression of bermudagrass in response to low temperature and salt stress. Ecotoxicology 2016, 25, 1-13. [CrossRef]

30. Fu, J.; Gates, R.N.; Xu, Y.; Hu, T. Diffusion limitations and metabolic factors associated with inhibition and recovery of photosynthesis following cold stress in Elymus nutans Griseb. J. Photochem. Photobiol. B 2016, 163, 30-39. [CrossRef]

31. Campos, P.S.; Quartin, V.; Ramalho, J.C.; Nunes, M.A. Electrolyte leakage and lipid degradation account for cold sensitivity in leaves of Coffea sp. plants. J. Plant Physiol. 2003, 160, 283-292. [CrossRef] [PubMed]

32. Hund, A.; Frascaroli, E.; Leipner, J.; Jompuk, C.; Stamp, P.; Fracheboud, Y. Cold Tolerance of the Photosynthetic Apparatus: Pleiotropic Relationship between Photosynthetic Performance and Specific Leaf Area of Maize Seedlings. Mol. Breed. 2005, 16, 321-331. [CrossRef]

33. Mir, B.A.; Mir, S.A.; Khazir, J.; Tonfack, L.B.; Cowan, D.A.; Vyas, D.; Koul, S. Cold stress affects antioxidative response and accumulation of medicinally important withanolides in Withania somnifera (L.) Dunal. Ind. Crops Prod. 2015, 74, 1008-1016. [CrossRef]

34. Megías, Z.; Martínez, C.; Manzano, S.; Barrera, A.; Rosales, R.; Valenzuela, J.L.; Garrido, D.; Jamilena, M. Cold-induced ethylene in relation to chilling injury and chilling sensitivity in the non-climacteric fruit of zucchini (Cucurbita pepo L.). LWT-Food Sci. Technol. 2014, 57, 194-199. [CrossRef]

35. Fan, H.; Du, C.; Xu, Y.; Wu, X. Exogenous nitric oxide improves chilling tolerance of Chinese cabbage seedlings by affecting antioxidant enzymes in leaves. Horticult. Environ. Biotechnol. 2014, 55, 159-165. [CrossRef]

36. Reinsberg, D.; Ottmann, K.; Booth, P.J.; Paulsen, H. Effects of chlorophyll a, chlorophyll b, and xanthophylls on the in vitro assembly kinetics of the major light-harvesting chlorophyll a/b complex, LHCIIb 1. J. Mol. Biol. 2001, 308, 59-67. [CrossRef]

37. Mohanty, S.; Grimm, B.; Tripathy, B.C. Light and dark modulation of chlorophyll biosynthetic genes in response to temperature. Planta 2006, 224, 692-699. [CrossRef] 
38. Xie, J.M.; Yu, J.H.; Huang, G.B.; Feng, Z. Relationship Between Carotenoid Content and Low-Light-Tolerance or Chilling-and Low-Light-Tolerance of Pepper Varieties. Sci. Agric. Sin. 2010, 43, 4036-4044.

39. Strasser, R.J.; Govindjee. The Fo and the O-J-I-P Fluorescence Rise in Higher Plants and Algae. In Regulation of Chloroplast Biogenesis; Springer: Boston, MA, USA, 1992; pp. 423-426.

40. Zivcak, M.; Brestic, M.; Kunderlikova, K.; Olsovska, K.; Allakhverdiev, S.I. Effect of photosystem I inactivation on chlorophyll a fluorescence induction in wheat leaves: Does activity of photosystem I play any role in OJIP rise? J. Photochem. Photobiol. B Biol. 2015, 152, 318-324. [CrossRef]

41. Ma, F.; Xu, T.T.; Chen, L.T.; Zhang, X.W.; Zhao, C.M. Functional Stability of Photosystem II in the Diploid Hybrid Species (Pinus densata) under Low Temperature Stress. Acta Botanica Boreali-Occident. Sin. 2011, 6,020 .

42. Haldimann, P.; Strasser, R.J. Effects of anaerobiosis as probed by the polyphasic chlorophyll a fluorescence rise kinetic in pea (Pisum sativum L.). Photosynth. Res. 1999, 62, 67-83. [CrossRef]

43. Xi, D.M.; Liu, W.S.; Yang, G.D.; Wu, C.A.; Zheng, C.C. Seed-specific overexpression of antioxidant genes in Arabidopsis enhances oxidative stress tolerance during germination and early seedling growth. Plant Biotechnol. J. 2010, 8, 796-806. [CrossRef]

44. Xu, Z.; Lei, P.; Pang, X.; Li, H.; Feng, X.; Xu, H. Exogenous application of poly- $\gamma$-glutamic acid enhances stress defense in Brassica napus L. seedlings by inducing cross-talks between $\mathrm{Ca}^{2+}, \mathrm{H}_{2} \mathrm{O}_{2}$, brassinolide, and jasmonic acid in leaves. Plant Physiol. Biochem. 2017, 118, 460-470. [CrossRef] [PubMed]

45. Zhang, S.; Jiang, H.; Peng, S.; Korpelainen, H.; Li, C. Sex-related differences in morphological, physiological, and ultrastructural responses of Populus cathayana to chilling. J. Exp. Bot. 2011, 62, 675-686. [CrossRef] [PubMed]

46. Murphy, C.; Wilson, J.M. Ultrastructural features of chilling-injury in Episcia reptans. Plant Cell Environ. 2010, 4, 261-265.

47. Fernando, N.; Alonso, J.M.; Ecker, J.R.; Julio, S. CBF2/DREB1C is a negative regulator of CBF1/DREB1B and $C B F 3 / D R E B 1 A$ expression and plays a central role in stress tolerance in Arabidopsis. Proc. Natl. Acad. Sci. USA 2004, 101, 3985-3990.

48. Chinnusamy, V.; Zhu, J.K.; Sunkar, R. Gene Regulation During Cold Stress Acclimation in Plants. Methods Mol. Biol. 2010, 639, 39-55.

49. Chinnusamy, V.; Ohta, M.; Kanrar, S.; Lee, B.H.; Hong, X.H.; Agarwal, M.; Zhu, J.K. ICE1: A regulator of cold-induced transcriptome and freezing tolerance in Arabidopsis. Genes Dev. 2003, 17, 1043-1054. [CrossRef]

50. Liu, L.; Duan, L.; Zhang, J.; Zhang, Z.; Mi, G.; Ren, H. Cucumber (Cucumis sativus L.) over-expressing cold-induced transcriptome regulator ICE1 exhibits changed morphological characters and enhances chilling tolerance. Sci. Horticult. 2010, 124, 29-33. [CrossRef]

51. He, X.; Sambe, M.A.N.; Zhuo, C.; Tu, Q.; Guo, Z. A temperature induced lipocalin gene from Medicago falcata (MfTIL1) confers tolerance to cold and oxidative stress. Plant Mol. Biol. 2015, 87, 645-654. [CrossRef]

52. Charron, J.-B.F.; Ouellet, F.; Houde, M.; Sarhan, F. The plant apolipoprotein D ortholog protects Arabidopsis against oxidative stress. BMC Plant Biol. 2008, 8, 86. [CrossRef] [PubMed]

53. Boca, S.; Koestler, F.; Ksas, B.; Chevalier, A.; Leymarie, J.; Fekete, A.; Mueller, M.J.; Havaux, M. Arabidopsis lipocalins AtCHL and AtTIL have distinct but overlapping functions essential for lipid protection and seed longevity. Plant Cell Environ. 2014, 37, 368-381. [CrossRef] [PubMed]

(C) 2019 by the authors. Licensee MDPI, Basel, Switzerland. This article is an open access article distributed under the terms and conditions of the Creative Commons Attribution (CC BY) license (http://creativecommons.org/licenses/by/4.0/). 